\title{
AN ESTIMATE OF THE COMMUTATIVITY OF $C^{2}$-FUNCTIONS AND PROBABILITY MEASURES
}

\section{TAKESHi MiUra, TAKahiro HaYATA AND Sin-Ei TAKAHASI}

Abstract. In [1], an estimate of the difference of the two sides of the Jensen's inequality with respect to probability measures was given, which is a special case of a Cauchy type mean value theorem (cf. $[3,4,5])$. Without Cauchy type mean value theorem, we give an estimate of the commutativity of $C^{2}$-function and probability measure. The purpose of this paper is to determine the equality condition for the estimate above.

Mathematics subject classification (2000): 26D15.

Keywords and phrases: Jensen's inequality, mean value theorem.

\section{REFERENCES}

[1] A. M. FinK, Estimating the defect in Jensen's inequality, Publ. Math. Debrecen, 69 (2006), 451-455.

[2] R. LARSEn, Banach algebras. an introduction, Marcel Dekker Inc., New York, 1973.

[3] A. MCD. Mercer, Some new inequalities involving elementary mean values, J. Math. Anal. Appl., 229 (1999), 677-681.

[4] J. E. PeČARIĆ, I. Perić AND M. SRIVASTAVA, A family of the Cauchy type mean-value theorems, J. Math. Anal. Appl., 306 (2005), 730-739.

[5] J. E. PeČarić, M. Rodić Lipanovič And H. M. SRivastava, Some mean-value theorems of the Cauchy type, Fract. Calc. Appl. Anal., 9 (2006), 143-158.

[6] W. Rudin, Real and complex analysis. Third edition, McGraw-Hill Book Co., New York, 1987. 